\title{
A Paradigm Shift: Adoption of Disruptive Learning Innovations in an ODL Environment: The Case of The University of South Africa
}

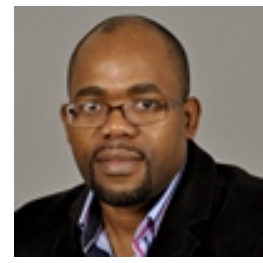

Blessing Mbatha

University of South Africa

\begin{abstract}
The aim of this article is to shed some light on patterns of and major motives for the adoption of different types of disruptive learning innovations by Unisa academics. To realise the aim of the study, the following questions were addressed: What are the reasons for adopting disruptive learning innovations? What is the level of interaction with disruptive innovations? What training do Unisa academics require on disruptive innovations? A qualitative approach was adopted by conducting focus group interviews with 76 Unisa academics. The data was analysed using open and axial coding, where dominant themes from the discussions were identified and discussed in detail. The findings show that the interaction of Unisa lecturers with different technologies varied from technology to technology. The study also found that disruptive innovations play a pivotal role in opening avenues and collapsing the transactional distance in an ODL institution. Some lecturers lack skill in using some technology, which is a cause for concern. Therefore, lecturers need to be trained in using technology and develop a good understanding of it to improve teaching and learning.
\end{abstract}

Keywords: Disruptive innovations; distance education; open distance learning; Web 2.0; new media; electronic learning; distributed learning 


\section{Introduction and Background to the Study}

Disruptive learning innovations pervade higher education. Consequently, higher education institutions are compelled to review their instructional, policy and technical frameworks to keep pace with these developments and to remain on par with global markets. Disruptive innovations are fundamentally transforming the education sector by replacing expensive, complicated and inaccessible products or services with much less expensive, simpler and more convenient alternatives such as Web 2.0 approaches (Mbatha, 2014; Huang, Hood, \& Yoo, 2014; Balakrishnan, 2014). There is no doubt that Information and Communication Technologies (ICTs), more especially disruptive innovations, have played and are continuing to play a pivotal role in enhancing the way teaching and learning are conducted. This transformation in education has been highly visible in distance education, where ICTs have been adopted to bridge the transactional distance between students and institutions.

The open distance learning (ODL) multi-dimensional system empowers prospective and/or current Unisa students to overcome the barriers of time, geographic positioning and the transactional divide between the institution and its stakeholders, particularly the students. ICTs with ubiquitous access to digital networks and the internet have radically changed the way information, especially multimedia information, is being stored, accessed and disseminated by information services (Geer \& Sweeney, 2012; Mbatha, 2013). This has been particularly relevant for institutions of higher education that find themselves having to review instructional, policy and technical frameworks to keep pace with these developments and to remain on a par with global markets. Mbatha (2014) further opines that new media tools have played and are continuing to play a pivotal role in redefining information and communication models used in the education of full-time, part-time, and life-longlearners.

\section{Problem Statement}

The problem that was investigated in this study relates to the inadequate use by some Unisa academics of disruptive learning innovations to enhance teaching and learning. These academics argue that they are unaware of such innovations and whether there are any benefits that can be reaped from adopting them. Some academics also argue vehemently that due to the poor telecommunications infrastructure that Unisa students have to face daily, it would be pointless to adopt technology for teaching and learning purposes (Mbatha, 2014). The main aim of the study is to shed some light on the Unisa lecturers' interaction with different types of disruptive innovation designed to enhance teaching and learning. This will contribute to the discussion about the future of learning agents: those professionals, paraprofessionals and other individuals

This work is licensed under a Creative Commons Attribution 4.0 International License. 
who help catalyse learning in the context of disruptive innovations. To realise the aforementioned aim, this article asks the following questions:

- What are the reasons for adopting disruptive learning innovations?

- What is the level of interaction with disruptive learning innovations?

- What training on using disruptive learning innovations do Unisa academics require?

After outlining the relevant literature on the power of disruptive learning innovations, the article reports on the theoretical framework on which this study article is based. The results are then reported and discussed, and the article ends with concluding remarks and recommendations.

\section{Literature Review}

The advent of emerging technologies in education has resulted in the birth of quite a number of concepts such as Web 2.0, new media and disruptive technologies, including disruptive innovations. "Disruptive innovation" is a term coined by Harvard Business School professor Clayton M. Christensen to describe a new technology that unexpectedly displaces an established technology (Christensen, 1997). Put rather simply, disruptive innovation is the introduction of new technologies, products or services in an effort to promote change and gain advantage over the competition. It is important to note that in this context, the word "disruptive" does not mean to interrupt or cause disorder, but rather "to replace" (Christensen, 1997). Modern examples of disruptive innovation include the development of mobile cellular telephones, digital cameras and e-book readers. Disruptive innovations cause a change or paradigm shift in business practices, markets and commerce and even consumers' lives.

Christensen describes disruptive innovations as technological innovations, products, services, processes, or concepts that disrupt the status quo. It did not take long for the term to be applied to education and to a variety of new tools and processes. Different writers have touted the Internet, wikis, blogs, social media, mobile devices, open source tools, open education, anytime/anywhere education, social bookmarking, sharing sites, wireless connections, Google, instant messaging, Internet telephony, social networks, free software, digital cameras and recorders, cloud computing, cheap storage, groupware, broadband, and virtual worlds as disruptive innovations in education, to name but a few (Flecknoe, 2002; Garrison \& Anderson, 2003; Garrison \& Kanuka, 2004; Shaikh, 2009). When people talk about the most significant innovations in society, they usually turn to examples that redefined how people go about their daily lives. For instance, an iPod has changed the way people purchase and listen to music, social media have changed how students communicate with each other, or camera-enabled smart phones have changed the way people document life around them. Each of these is an example of

This work is licensed under a Creative Commons Attribution 4.0 International License. 
disruptive innovation, a term that most commonly is used to describe how certain technologies have introduced radically different behaviors into society.

Already in higher education, online learning is beginning to disrupt the old ways of doing things (Flecknoe, 2002; Garrison \& Anderson, 2003). Online education is not bound by location or the same time constraints; thus previously unserved individuals have taken advantage of educational experiences. Institutions have acquired new students and saved money by serving courses virtually rather than in classrooms (Mbatha, 2014). As technology and courses have improved, more students have begun to take online courses alongside regular face to face classes. Some online classes even allow students to experience similar interactive class activities, and sometimes previously impossible activities.

\section{The Role of Disruptive Innovations in Higher Education}

Emerging technologies have proved to be a force to be reckoned with in so far as transforming teaching and learning are concerned. The major role of these technologies in education is to empower the technology to present educational activities. ICTs allow open source learning rather than manual source learning, thus encouraging students to learn new ideas. The innovative tools also bring about active learning and encourage collaborative, creative, integrative and evaluative aspects in the education sector (Mbatha, 2014). Likewise, in his earlier study, J orge (2002) postulates that ICTs provide a great development opportunity by contributing to information dissemination, providing an array of communication capabilities and increasing access to technology and knowledge, among other things. Recent studies on the diffusion and adoption of ICTs in higher education recommend that a robust ICT infrastructure be made available to enable all stakeholders involved in the teaching and learning process to use e-learning systems effectively (Mbatha, 2014). It was confirmed by Tiene (2002), more than a decade ago, that ICT integration in higher education is critical for the social and economic progress of any country.

Similarly, Shaikh (2009) argues that social and economic progress can be achieved through knowledge that can be archived by adopting ICTs for teaching and learning. He also adds that with the help of ICTs, higher education is the most powerful tool for the creation of that knowledge and hence a knowledge-based society. ICTs have brought about drastic changes in the facilitation of education and revolutionised the way teaching and learning are conducted. However, it is important to note that for a visible and effective revolution to take place in higher education, changes will have to occur that will disrupt the status quo. These changes may be a form of transformation that is already occurring in global universities. Mbatha (2013) contends that higher education is in the process of transition, from the traditional model of learning to a new, socially mediated model. In line with these views, Maree (2011) argues that the new, socially mediated model has been spearheaded by the advent of new media tools such as Web 2.0 approaches. 


\section{Research Methodology}

The study reported on here falls within the qualitative paradigm, and face-to-face interviews were conducted in order to encapsulate the viewpoints of the target population, which comprised 76 Unisa academics. The interviews provided academics with an opportunity to share and reflect on their perceptions and experiences of the use of disruptive learning innovations in an ODL context. These audio-taped interviews lasted from 30 minutes to one hour, and were held at Unisa. Given the diverse nature and large size of the Unisa community, the researcher narrowed down the focus of this study to Unisa's main hub, which is located in Pretoria (Tshwane) in South Africa. A purposive sampling was used to select the participants. The data was analysed using axial and open coding, where dominant themes from the discussions were identified and discussed in detail (Strauss \& Corbin, 1998).

Data analysis was divided into two phases. In the first phase, the researcher engaged in "open coding" in order to generate thematic categories, thereby reducing large passages of text to principal concepts. In the second phase, the researcher engaged in "axial coding" in which he formed concrete codes for analysis. The study sought to generate a rich body of findings from a smaller number of participants, rather than less detailed information from a larger group. While the study's findings may not be representative or generalisable, they indicate areas for further exploration and contribute to the development of strategies that can be implemented to improve the use of technology in education. The validity of the interview guide was enhanced by the fact that the questions were based on the objectives of this research study. Each question was checked to determine whether it contributed to the research objectives. As far as internal validity was concerned, the researcher scrutinised the work critically to ensure that the research assistants adhered to the topic and thus that the study measured what it was intended to measure. Internal validity was also ensured by reviewing studies by other researchers in the same field. With regard to reliability, the research instrument was pre-tested in a pilot study for clarity, completeness, relevance and shortcomings. The pilot study aimed to test the subject matter of the current research, the population it was to cover, its spatial variability, and respondents' possible reactions to questions.

In terms of ethical considerations, informed consent was obtained from all participants in the study to ensure that they understood what they were doing and to verify their willingness to participate. The participants were informed of their rights, including the right of consent; protection from disclosure of information; and respect for their privacy. The researcher ensured that the participants were not exposed to risk or embarrassment, unusual stress or any demeaning treatment. Anonymity and confidentiality were promised and maintained. All the research participants participated voluntarily. The information the participants provided was not made available to those who were not directly involved in the study and it could not be traced to/associated with the participants. The researcher also ensured that the participants remained anonymous throughout the study. In terms of professional standards, the researchers ensured 
that the results were gathered in a professional manner, without misrepresenting anyone and/ or intentionally misleading the participants about the nature of the study. The researcher ensured that all the findings were presented honestly, without fabricating any data to support a particular finding.

\section{Findings and Discussion}

The findings below are reported under the following headings: reasons for adopting disruptive learning innovations; level of interaction with disruptive innovations; and academics' training needs regarding disruptive innovations.

\section{Reasons for Adopting Disruptive Innovations}

One of the objectives of the study was to establish the major motives of Unisa academics for adopting disruptive learning innovations in their teaching. The main aim of this objective was to capture the pedagogical value of disruptive innovations so that those who are unaware of the role of these tools could be made aware of them. It emerged during the interviews that Unisa academics use disruptive innovations for a variety of educational reasons. This is good for an ODL system where different kinds of technology are continuing to play a pivotal role in helping academics to facilitate teaching and learning. For example, one of the participants commented: "You see, since the advent of new media I decided to incorporate them in my teaching, basically I use disruptive innovations to collaborate with my students and colleagues."

This finding is in line with many studies that have been conducted on the educational value of new media. These studies have confirmed that disruptive learning innovations are catalysts when it comes to improving collaborations in education (Stanciu, Mihai, \&Aleca, 2012). In concurrence with these views, Huang, et al. (2010) argue that many researchers try to use the trend of Web 2.0 to promote a new learning model, for example applying blogs in learning and conducting knowledge-sharing through blogs (J acobs, 2003; Bruns \&J acobs, 2006). Likewise, Huang, J eng, and Huang (2009) note that collaborative learning can be supported by blogs. In addition, the study found that one of the reasons academics use disruptive innovations is the need to improve interaction with students and other academics. This came out strongly during the interviews, where one of the participants mentioned the following: "I use disruptive innovations interaction with my students as I do not have an opportunity to physically meet with them like it is the case in contact universities."

In concurrence with the above finding, Paily (2013) supported by Mbatha (2013) notes that new media tools can be used in education to improve interaction between learners and educators. These findings suggest that disruptive innovations are indeed some of the change agents that have unquestionably transformed the way teaching and learning are carried out. It is of the utmost

This work is licensed under a Creative Commons Attribution 4.0 International License. 
importance to note that ever since the advent of new media, many global tertiary institutions have witnessed a strong transition in teaching and learning. More online tertiary institutions have emerged as a result of new media because the diffusion and adoption of these tools in education have enabled universities to reduce costs in the way they deliver education; collaborations have drastically improved; and information sharing and access have also immensely improved (Fang \& $\mathrm{Li}$, 2013; Mbatha, 2014). On the other hand, these tools are capable of bridging the transactional distance between the institution and the students, offering easy access to tutorial matter. This is more evident in an ODL environment such as Unisa. In support of these findings, the issue of using disruptive innovations to reduce cost was a talking point during the interviews. For example, one of the participants, who was supported by others, mentioned:

"Other than improving interaction with my students, I use technology to reduce costs, and most of our students are not working, hence they can't afford to travel and buy textbooks. I use new media to share with them study material, even research articles I just post them on social networks, sometimes a link is enough."

Another area where disruptive innovations are playing a fundamental role is the facilitation of communication. Since the advent of the internet and new media tools communication has drastically improved (Fang \& Li, 2013; Mbatha, 2013). This fact was also evident during the interviews: one of the participants commented: "Since the advent of new media applications the way people communicate has drastically improved."

In support of this finding, another participant shared the following:

"One of the main reasons I use disruptive innovations is to improve communication with my students. This has been very useful given the fact that my students are all over the world and what a better to communicate with them other than these tools."

\section{Levels of interaction with Disruptive Innovations}

It is believed that if the level of interaction with disruptive learning innovations is high, the level of work productivity and creativity will also improve (Mbatha, Ocholla, \& Le Roux, 2011). Hence participants were asked to comment on their level of interaction with disruptive learning innovations at Unisa. The aim of this question was to establish the extent to which academics interacted with technology to enhance teaching and learning. For example, one of the participants said: "I make use of quite a number of disruptive innovations but the one that stands out for me is Google search as my level of interaction with it is very high."

It emerged during the interviews that academics' level of interaction with new media tools such as smartphones, YouTube, and Google search was very high. These findings tie in well with the 
studies conducted by Wakari and Ocholla (2010), who note that mobile phones are by far the most popular ICT tools in Africa, citing very well-known reasons such as access, functions, availability, easy usage and ownership. Mobile phones are easy to operate and provide immediate opportunities for communication with others with no limits on time and space.

Rogers (1995) explains why some innovations are adopted and others are not. He describes an innovation as an idea, practice or object that is perceived as new by an individual or other unit of adoption. He found that the rate of adoption of an innovation is influenced more by an individual's perception of the newness of an innovation than by the actual time it has been around. He further observes that "newness" can also mean new knowledge of the innovation or a new decision to adopt it. In essence, what Rogers means here is that computers may be considered as innovations - even though they have been available to the public for almost 25 years - whenever someone makes a new decision to purchase one. Therefore, one can still expect to see academics adopting disruptive learning innovations such as shared documents, bookmarks and Skype, to name but a few.

Strangely, the findings suggest that many participants were not using social networks to enhance teaching and learning. However, many studies have confirmed that social networks have transformed the way teaching and learning are conducted (Mbatha \& Manana, 2012; Stanciu, Mihai, \&Aleca, 2012). There is no doubt that social networking is a powerful force: the world has recently witnessed the power of Facebook, Twitter and other microblogging tools even in such developing countries as Egypt and Libya. The education sector has kept pace with the latest technological developments and is benefiting from this amazing tool. A study conducted by Stanciu, Mihai, and Aleca (2012) revealed that 49\% of Facebook users and 55\% of Twitter users are involved in educational activities in high schools or universities, and another $25 \%$ have already graduated. In support of these views, Mbatha (2014) argues that social networks have become a force to be reckoned with in education, more especially in an ODL context where there is a transactional distance to be bridged.

Obviously, disruptive learning innovations such as social networks often still include information that might not be strictly relevant to users. For example, some lecturers and students on Facebook and Twitter provide continuous status updates about their families, holidays, weekend activities and other interesting but often meaningless information, and sometimes personal information that has nothing to do with teaching and learning. This problem may stem from the fact that some institutions have no policy on the use of social networking for educational purposes, and Unisa is no exception. Other lecturers are sceptical about using these sites due to security concerns. Allowing students to collaborate online is simply too risky for some lecturers. They are afraid if a student does something unforeseen which may raise an unethical or illegal issue, lecturers could lose their jobs as a result. Administrators often cannot help the situation because most of them do not understand how these sites work and the educational value they can provide.

This work is licensed under a Creative Commons Attribution 4.0 International License. 
However, the findings of this study paint a different picture. For example, one participant who was supported by many indicated: "Eish social networks are not for me, although I sometimes use them to interact with my students but I use them sparingly."

Conversely, some of the participants were using social networks to improve teaching and learning. These academics understood the educational value of the tools. A study by Casquero, et al. (2010) confirms that complementary to virtual classes, accessing social networks as learning environments has become a basic concept for e-learning 2.0 frameworks. The main role of social networks is to combine virtual learning communities within the scope of discussions on topics such as scientific subjects, virtual experiments or other various themes as exam preparation (Casquero, et al, 2010). For example, one of the participants shared the following: "I mostly use social networks such as Facebook and Twitter because almost all my students have access to them."

In line with these findings, a study that was conducted by Liebenberg, Chetty, and Prinsloo (2012), established that out of 22,216 Unisa students who participated in the study, $91 \%$ had regular access to the internet, while 22,000 had access to computers. These results show that Unisa students have access to the relevant technologies required to study through Web 2.0 tools such as social networks. The use of social networks to bridge the communication gap between teacher and learner has been identified as one of the most significant features of ODL delivery systems (Ofulue, 2011; Paily, 2013; Fang \& Li, 2013; Mbatha, 2013; Olive, 2013). Liebenberg and Chetty (2011) observe that there has been an explosion in collective sharing and generation of knowledge as a result of growing numbers of connected people and the proliferation of Web 2.0 approaches.

\section{Academics' Training Needs Regarding Disruptive Innovations}

In this item, participants were asked to comment on the type of training they would require in order to help them use ICTs more often and effectively to improve teaching and learning at Unisa. Computer illiteracy is regarded as one of the barriers to the use of ICTs (Mbatha \& Naidoo, 2010). Ofulue (2011) is of the view that South Africa has a similar experience to the rest of Africa with regard to the need for increased access, which is one of the main reasons distance education remains an attractive option. At the same time and in contrast to the rest of the continent, South Africa has a relatively longer history in the use of distance education and - in varying degrees across institutions - the use of ICTs in higher education. However, the literature suggests that access cannot be provided through the use of ICTs in the same way as in developed countries (Ofulue, 2011). Although some of the participants did not require training in any types of new media, most of them indicated that they were digital immigrants and would love to be trained on how to apply these tools in education. For example, one of the participants said: "I am more interested in getting more training on how to use vodcasts and podcasts to improve teaching and learning."

This work is licensed under a Creative Commons Attribution 4.0 International License. 
It is no wonder that some of the participants needed training on how to use vodcasts and podcasts to improve teaching and learning. These tools have emerged in academia and are regarded as key when it comes to presenting classes; they can be very effective in an ODL landscape where there is a transactional distance between a learner and an instructor. One of the advantages of vodcasts or a podcasts is that they can be used over and over again. Some ODL experts believe that vodcasts and podcasts are some of the new media tools that all academics in ODL institutions should use to transform teaching and learning (Mbatha \& Manana, 2012).

Also of note is that there was a demand for training on how to apply multimedia in education. For example, one of the participants said: "I need training on how to apply multimedia sharing on my teaching as I always hear people praising it."

Indeed multimedia sharing has taken the world by storm and the education system has not been left behind in this regard. ODL and multimedia are inseparable. It is said that multimedia sharing makes teaching and learning a more enjoyable experience for students. Some of the participants needed training on how to use Google docs. One participant commented:

"For me it has to be Google docs/drive, my students always ask me to post some of the articles on Google drive so that they could access them wherever they are, although I registered for it but I have never used it for educational purposes."

Some researchers argue that Google docs/drive has simplified the sharing of information and collaboration more than any other tool (Mbatha \& Manana, 2012; Mbatha \& Naidoo, 2010). In line with these views, Mbatha (2014) notes that since the advent of Google docs, there has been a rise in the number of people who share documents and collaborations have also drastically improved. Similarly, many participants indicated a need for training on how to use Dropbox to enhance teaching and learning. Dropbox has seen a rise in user numbers and has also been buttressed by numerous researchers as catalysts when it comes to collaboration and sharing of information. One of the advantages of these tools is the fact that they are accessible without cost and one only needs a computer and an internet connection to access them; as a result they are widely used by students all over the world. This came out strongly during the interviews; as one of the participants said: "If I can be trained on how to use Dropbox to enhance teaching and learning, I would be happy."

It is true that information retrieval is not a given to be any academic's or student's crowning glory. However, it is a skill that needs to chiselled and improved by every training method on offer. Hence it was no wonder that one of the participants said: "I don't know much about new media tools, but I would be happy if I could get trained on how to search for information such as journal articles using databases." 


\section{Conclusion and Recommendations}

The aim of this article was to shed some light on patterns of and major motives for the adoption of different types of disruptive learning innovation by Unisa academics. To realise the aim of the study, three questions were posed, namely: what are the academics' motives for adopting disruptive learning innovations? What is the level of interaction with disruptive innovations? What training do Unisa academics require in order to use disruptive learning innovations more effectively?

Increasingly, tertiary institutions all over the world are adopting new media in order to carry out their activities and operations, resulting in what is commonly known as electronic learning. Ultimately, for academics to be able to deliver services quickly and efficiently, they need to have access to the relevant new media tools. With regard to the motives of Unisa academics who adopt disruptive learning innovations in their teaching, it emerged during the interviews that they do this for a variety of educational reasons. This is good for an ODL system where different kinds of technology continue to play a pivotal role in helping academics to facilitate teaching and learning. Many Unisa academics use these tools to improve collaboration with their students and colleagues. Also of note is that academics have adopted these tools in their teaching in order to facilitate interaction with their students.

Notwithstanding the fact that not all Unisa academics have adopted these tools for teaching and learning purposes, those who have done so seem to understand the pedagogical value these tools have in an ODL context. Even the literature confirms that these tools have been buttressed by numerous researchers as catalysts in bridging the transactional distance in an ODL landscape. It is therefore safe to say that disruptive innovations are change agents that have palpably enhanced the way teaching and learning are conducted. It is also important to note that the study found that cost reduction was one of the main reasons why academics decided to adopt disruptive innovations in their teaching. This is one area where technology has played a major role, and is more evident in ODL institutions where a variety of new media approaches have been adopted to make teaching and learning easier, more convenient, and a more enjoyable experience for both lecturers and students. Unsurprisingly, one of the motives for academics to use disruptive innovation in their teaching was to facilitate communication with their students. Disruptive innovations have proved to be vital in the facilitation of communication and this has resulted in the rise of new communication tools.

In so far as the academics' level of interaction with disruptive innovations is concerned, it emerged during the interviews that academics' level of interaction differed from technology to technology. For instance, the level of interaction with disruptive innovations such as Google search, smartphones and YouTube was intense, whereas with social networks, Skype and podcasts, to name but a few, it was the total opposite as a number of academics used them sparingly. Therefore, it is important that academics are sensitised to and made aware of the

This work is licensed under a Creative Commons Attribution 4.0 International License. 
importance of the constant use of social networks to improve teaching and learning. This article argues that if the level of interaction with disruptive learning innovations is high, the level of work productivity and creativity is most likely to improve, which positively impacts on throughput.

In order to use any technology effectively, a person must be equipped with the necessary skills. The issue of computer skills has always been a serious one in many countries, and South Africa is no exception. This is evident in the number of academics who indicated different areas of training that they required in order to help them use disruptive learning innovations more often and more effectively to improve teaching and learning. The most urgent training needs were in the application of vodcasts, podcasts, multimedia and Dropbox. Based on these findings, the study concludes that as technology continues to evolve, so does the need for training in the use of disruptive learning innovations to enhance teaching and learning. This article recommends that training sessions for academics be conducted so that they can use the ICT knowledge and skills thus acquired in their daily work and activities. Due to tertiary institutions' on-going move towards the ODL culture, they have to be involved in programmes that will help them serve their students effectively with the ICT-related services they require.

Based on the findings, it is important to note that if universities wish to diffuse and adopt the use of disruptive learning innovations, a number of important issues need to be addressed first. The first issue involves training academics to be able to use technology effectively. Some of the academics indicated that a lack of computer skills was hampering their interaction with disruptive innovations. Equally important is the need for a well-developed and efficacious ICT policy and proper planning for the adoption and diffusion of relevant disruptive learning innovations that would improve teaching and learning. Without an ICT policy, universities cannot improve teaching and learning and this might also negatively affect their throughput. This article argues that the challenges faced by academics when using disruptive learning innovations could be easily contained with the existence of a comprehensive policy. This study targeted only academics at Unisa. Therefore, future studies should focus on the perceptions, experiences and views of students to complete the picture for adoption of disruptive learning innovations to improve teaching and learning. 


\section{References}

Balakrishnan, V. (2014). Using social networks to enhance teaching and learning experiences in higher learning institutions. Innovations in Education and Teaching International, 51(1), 595-606.

Bruns, A., \&J acobs, J . (2006). Uses of blogs: Volume 38 of Digital formations. New York, NY: Peter Lang.

Casquero, O.J , Portillo, R., Ovelar, M., Benito, M. \& Romo, J. (2010). "iPLE Network: an integrated eLearning 2.0 architecture from a university's perspective". Interactive Learning Environments, 18(3), 22-39.

Christensen, C. M. (1997). The innovators dilemma: when new technologies cause great firms to fail. Boston: Harvard Business School Press.

Fang, H., \& Li, X. (2013). Web 2.0 application in subject services of high school libraries. Information Technology J ournal, 2(2), 458-461.

Flecknoe, M. (2002). How can ICT help us to improve education? Innovations in Education \& Teaching International, 39(4), 271-280.

Garrison, R. \& Anderson, T. (2003). E-learning in the 21st century: A framework for research and practice. London UK: Routledge Falmer.

Garrison, D.R. \& Kanuka, K. (2004). Blended learning: Uncovering its transformative potential in higher education. Internet and Higher Education, 7(2), 95- 105.

Geer, R., \& Sweeney, T. (2012). “Students' Voices about Learning with Technology”. J ournal of Social Sciences, 8(2), 294- 303.

Huang, W. D., Hood, D. W., \&Yoo, S. J . (2014). Motivational support in Web 2.0 learning environments: a regression analysis based on the integrative theory of motivation, volition and performance. Innovations in Education and Teaching International, 51(3), 631-641.

Huang, YM., J eng, Y.L. \& Huang, T.C. (2009). An educational mobile blogging system for supporting collaborative learning. Educational Technology \& Society, 12(2), 163- 175.

J acobs, J . (2003). Communication over exposure: The rise of blogs as a product of cybervoyeurism. In C. J . Hatcher, J . J acobs \& T. Flew (Eds), Australian and New Zealand Communication Association Conference Proceedings, pp. 23- 35. Brisbane. 
J orge, S. N. (2002). The economics of ICT: challenges and practical strategies of ICT use for Women's economic empowerment. Seoul: United Nations Division for the Advancement of Women (DAW).

Liebenberg, H. \& Chetty, Y. (2011). Report: Student ICT Survey Results: Collaboration between DISA and ICT. Unisa: Department of Information \& Strategic Analysis.

Liebenberg, H., Chetty, Y. \& Prinsloo, P. (2012). Student access to and skills in using technology in an open and distance learning context. The International Review of Research in Open and Distance Learning, 13(4), 249- 268.

Maree, C. (2011). Exploring the implications, challenges and potential of new media and learning. On the Horizon, 19(1), 245- 252.

Mbatha, B.T. \& Naidoo, L. (2010). Problems hampering the collapse of distance in ODL, Progressio, 32(1), 170- 184.

Mbatha, B. T., Ocholla, D. N., \& Le Roux, J . (2011). Some implications of information and communication technologies on public service work environments in South Africa. Information Development, 27(2), 47- 62.

Mbatha, B.T. \& Manana, K.P.P. (2012). Students' perceptions on the use of Facebook in an ODL landscape. Progressio, 34(1), 13- 26.

Mbatha, B. T. (2013). Facebook: The power source of transforming the learning experience. International J ournal for e-Learning Security, 3(1), 23- 39.

Mbatha, B. T. (2014). Global transition in higher education: From the traditional model of learning to a new socially mediated model, the case of the University of South Africa. International Review of Research in Open and Distance Learning, 12(2), 25- 36.

Ofulue, C.I. (2011). Survey of barriers affecting the use of information communication technologies among distance learners: a case study of Nigeria. Turkish Online J ournal of Distance Education, 12(3), 145- 154.

Olive, J . (2013). Dynamic and interactive mathematics learning environments: Opportunities and challenges for future research. Mevlana International J ournal of Education, 3(3), 8- 24.

Paily, M. U. (2013). Creating constructivist learning environment: role of "Web 2.0" technology. International Forum of Teaching and Studies, 9(1), 39- 50.

Rogers, E. M. (1995). Diffusion of innovations. New York: Free Press. 
Shaikh, Z. A. (2009). Usage, acceptance, adoption, and diffusion of Information \& Communication Technologies in higher education: a measurement of critical factors. J ournal of Information Technology Impact, 9(2), 63- 80.Strauss, A., \& Corbin, J . (1998). Basics of qualitative research: Techniques and procedures for developing grounded theory (2nd ed.). Thousand Oaks, CA: Sage Publications.

Stanciu, A., Mihai, F., \&Aleca, O. (2012). Social networking as an alternative environment for education. Accounting and Management Information Systems, 11(1), 56- 75.

Tiene, D. (2002). Addressing the global digital divide and its impact on educational opportunity. Educational Media International, 39(1), 211- 222.

Wakari, G. \& Ocholla, D.N. (2010). The diffusion and Impact of mobile phones on the informal sector in Kenya. Proceedings of the 11 ${ }^{\text {th }}$ DIS Annual Conference 2010, 2- 3 September, University of Zululand, Richards Bay, South Africa.

(C) Mbatha

\section{Athabasca University $\mathbf{a}$}

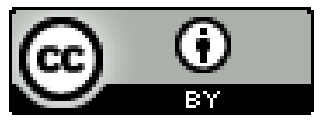

